\title{
The Role of the Human Papillomavirus (HPV) in Cervical Cancer: A Review about HPV-Induced Carcinogenesis and Its Epidemiology, Diagnosis, Management and Prevention
}

Karl Bonello,' Renald Blundell.'

\begin{abstract}
The human papillomavirus (HPV) was the first virus known to induce carcinogenesis and is associated with cancers of the uterine cervix, anogenital tumors and malignancies of the head and neck. This paper reviews the structure and basic genomic characteristics of the virus and outlines the clinical involvement of the main HPV serotypes, focusing on the carcinogenic role of HPV-16 and 18. The mechanisms that occur in the development of cervical neoplasia due to the oncogenic proteins $E 6$ and $E 7$ which interfere with the regulation of the cell cycle through their interaction with p53 and retinoblastoma protein are described. Epidemiological factors, diagnostic tools and the management of the disease are also reviewed, along with the available vaccines to prevent the viral infection. Insights on current research on involvement of oxidative stress and micro-RNAs in cervical carcinogenesis are also explored as they may unlock new means of diagnosis and treatment in the future.
\end{abstract}

Keywords: Human papillomavirus 16; Human papillomavirus 18; Uterine Cervical Neoplasms; Biomarkers; Papillomavirus Vaccines (Source: MeSH, NLM).

About the Author: Karl Bonello is currently a fifth-year medical student of a five-year program at the University of Malta Medical School, Msida, Malta. He is also a recipient of a Dean's Award during his second year of study and an Academic Award from the University of Malta Student Council in his fourth year. He ranked first place in his year group over the first four years of the program.

\section{Introduction}

The human papillomaviruses (HPVs) are a group of small viruses containing deoxyribonucleic acid (DNA) which belong to the Papillomaviridae family. They are highly ubiquitous and properly adapted to their hosts, with the ability to effectively mask themselves from immune responses. Over 200 types of viruses have been identified and classified into 16 genera, and most of these affect humans. These viruses primarily target differentiating squamous epithelium and are associated with cutaneous infections, in which almost any part of the human skin can be affected, and mucosal infections. HPV infection is a risk factor for malignancy of the uterine cervix by playing an integral role in carcinogenesis through the action of its genomic products.

\section{HPV Structure}

HPVs are spherical, non-enveloped particles with an approximate diameter of $52-55 \mathrm{~nm}$ and a molecular weight of about $5 \times 10^{6}$ Da. Their capsid has an icosahedral symmetry and is composed of 72 capsomeres, each possessing five identical subunits and hence a five-fold symmetry. ${ }^{2}$ of these capsomeres, 60 are hexavalent (exhibit six-coordination), whilst the remaining 12 are pentavalent. ${ }^{3}$

\section{The HPV Genome}

The nucleic acid core of the virion consists of supercoiled double-stranded closed circular DNA of approximately 8,000 base pairs. The open reading frame (ORF) size is larger than 400 bases and found on one strand exhibited in the form of arcs external to the circular genome. All viral messenger ribonucleic acid (mRNA) transcripts are derived from one strand. ${ }^{4}$
Both the capsid and genome morphology are similar across the Papillomaviridae family, but differences in the genomic organization as well as size and sequences of nucleotides and amino acids have allowed the separation of papillomaviruses into separate groups. ${ }^{5}$

The genome of all papillomaviruses consists of three unequal regions. The upstream regulatory region (URR) is also known as the long control region (LCR) or the non-coding region (NCR) and constitutes around $10 \%$ of the entire genome. ${ }^{3}$ The early region occupies approximately half the genome and is further divided into two large and many smaller reading frames: E1-E2 and $\mathrm{E}_{4}-\mathrm{E} 7$, respectively. ${ }^{3} \mathrm{E} 6$ and $\mathrm{E} 7$ are directly involved in the development of cervical cancer. ${ }^{2}$ The late region completes the remaining $40 \%$ of the genome and contains two genes: L1 and $\mathrm{L} 2 .^{3}$

\section{HPV Classification and Serotypes}

Although HPV is commonly implicated in cases of cervical cancer, this is not the sole clinical scenario in which the virus is involved. There is a great diversity of HPV types that cause various lesions, which may overlap across the different types. HPV serotypes are genetically diverse from each other and, in fact, the standard systematic classification system states that a specific HPV type must possess a complete genome in which the L1 nucleotide sequence differs from that in any other HPV genome by a minimum of $10 \%$. HPV types are denoted numerically, in the chronological order of when they were discovered. ${ }^{2}$ There are over 200 types of HPV and these are further classified into 16 genera.' There are further subdivisions known as HPV 
species, which represent serotypes that are genetically distinct but are characterized by similar biological activity. In addition, there are also other HPV subtypes and variants that are $2-10 \%$ and $<2 \%$ dissimilar. ${ }^{2}$

Due to the fact that there is a multitude of HPV serotypes and that they have evolved to occupy various biological niches, ${ }^{2}$ they are often divided into three groups: cutaneous, mucocutaneous, and the viruses associated with epidermodysplasia verruciformis.' The Beta genus encompasses the cutaneous HPVs, together with some members of the Gamma and Mu genera. The Alpha genus is mainly characterized by the mucosal serotypes but also some cutaneous types that cause warts. ${ }^{5}$ HPVs can also be grouped depending on the regions of the body that they infect and the diseases they cause. ${ }^{2}$

There is yet another classification system for HPVs based on their oncogenic potential. In this system, the viruses are divided into three groups depending on whether they cause an infection which has a low, intermediate or high risk of resulting in a malignancy, 5 as can be seen in Table 1.

\section{Epidemiology}

The anogenital type of infection is the most common sexually transmitted infection (STI) in the United States-it is estimated that 6.2 million people acquire the infection every year. The infection tends to be more common in adolescents and young adults. Clinical studies have shown that the prevalence in adolescent girls is normally around $30 \%$ and can even go up to $64 \%$. Another study explained that four years after first sexual intercourse, over half of the young woman population were affected by cervical HPV infection. The same study also reported that HPV can be transmitted via nonpenetrative sexual behavior, but the probability is lower than acquiring the infection through penetrative sex. Apart from sexual behavior and history, studies in the United States reported that an age of less than 25 years is also a risk factor for the infection and the prevalence tends to decrease after this age, except for one cohort study in Costa Rica, which found that the prevalence rises again after 40. Furthermore, men and women seem to have similar rates of HPV infection. ${ }^{6}$ Figure 1 illustrates the prevalence of HPV infection according to age.

The detection of high-risk HPV in virgins, neonates and children provides evidence that the sexual route is not the sole means of HPV transmission. Both low- and high-risk HPV serotypes can be transmitted via non-sexual routes such as physical contact, shared bathing and infected fomites. It appears that the transmission of high-risk HPV from mother to infant occurs during parturition as the neonate descends through the infected birth canal. This is more likely to occur in women having markedly higher amounts of HPV DNA, such as HPV-16, than in those having less DNA. Furthermore, a case of two mothers with both HPV-16 and 18 infections gave birth to neonates with similar co-infection.?

The state of pregnancy seems to increase the likelihood of developing genital HPV infections. This was demonstrated by a study which showed that $52.5 \%$ of patients tested positive for HPV DNA during the third trimester of pregnancy, compared to $17.5 \%$ after parturition. Physiological explanations for
Table 1. HPV Serotypes Grouped according to Oncogenic Risk

\begin{tabular}{lll}
\hline Risk Category & \multicolumn{1}{c}{ HPV Serotype } & \multicolumn{1}{c}{ Relation to Cervical Cancer } \\
\hline Low & 6,11 & $\begin{array}{l}\text { Rarely associated with cervical cancer and mostly causes } \\
\text { genital warts }\end{array}$ \\
Intermediate & $22,35,39,52,56$, & $\begin{array}{l}\text { Present in around } 25 \% \text { cases and are rarer than the high-risk } \\
\text { serotypes }\end{array}$ \\
High & $16,59,68$ & $\begin{array}{l}\text { Present in around } 75 \% \text { of cases, the commonest types being } \\
16 \text { and } 18\end{array}$ \\
\hline
\end{tabular}

Adapted from Blundell R, Camilleri G. The human papillomaviruses (HPVS) and HPV DNA testing. In: Blundell R, ed. Infertility. Saarbrücken (Germany): Lambert Academic Publishing; 2013. p. 57-82. Reprinted with permission from Blundell $R$.

Figure 1. Prevalence of High-Risk HPV Infection among Females Undergoing Cervical Screening

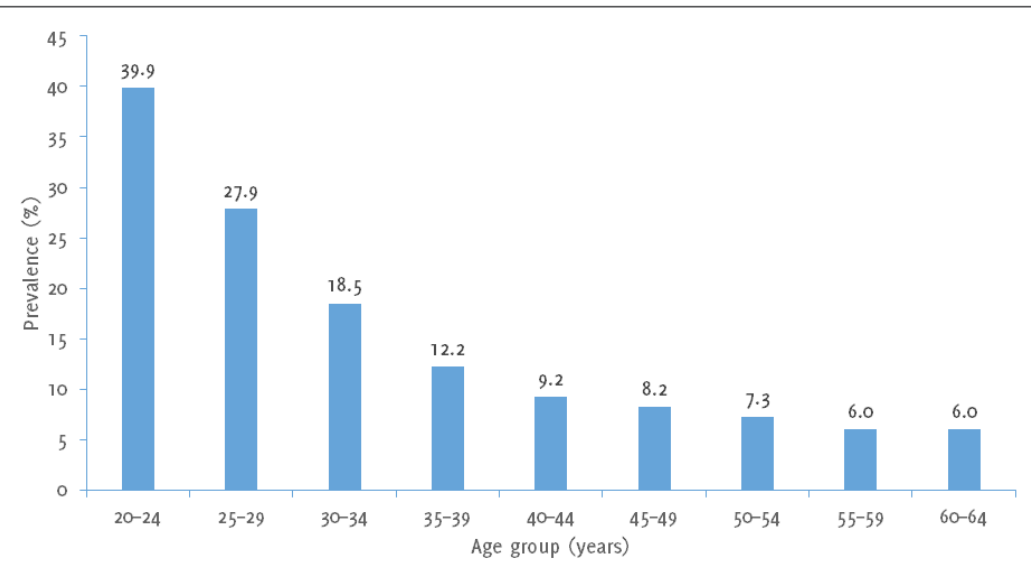

Compiled using information from Kitchener $\mathrm{H}$, Almonte $\mathrm{M}$, Wheeler $\mathrm{P}$, Desai M, Gilham C, Bailey $\mathrm{A}$ et al. HPV testing in routine cervical screening: cross sectional data from the ARTISTIC trial. Br J Cancer. 2006;95(1):56-61.

this finding may be that the hormone profile during pregnancy increases the transcription of HPV genes due to interactions between glucocorticoids and their response elements present in the non-coding region of HPV- 16 . Additionally, pregnancy is a state of immunosuppression. HPV infections can also be transmitted during pregnancy itself across the placenta and through amniotic fluid. In fact, a study revealed the presence of HPV DNA in $75 \%$ of amniotic fluids taken from women who were positive for cervical HPV DNA.?

Interestingly, the first evidence that suggested an association between HPV and cancer emerged from research in the 1970 S on skin cancer in patients suffering from epidermodysplasia verruciformis, ${ }^{4}$ which is a rare autosomal recessive disorder associated with the mutation of one of the two genes: EVER1 and EVER2 located on chromosome 17.' This disorder is characterized by flat warts or pityriasis-like lesions that are caused by infections with HPV types 5, 8 or 17. These warts resulted in skin cancers in $20 \%$ of patients, mostly in areas exposed to the sun. ${ }^{4}$ It appears that the mutated genes code for transmembrane proteins that function in zinc homeostasis, and their loss results in the transcription of the E6 and E7 genes, 'thereby facilitating carcinogenesis.

Cervical cancer is the second most common malignancy in women around the world and affects an average of 35 per 100,000 women.' The interest in the association between HPV and cancer was greatly magnified when HPV types 16 and 18 were discovered in cervical cancers and preneoplastic dysplasia, 
lesions that can predispose one to malignancy of the uterine cervix. ${ }^{4}$ It has been found that HPV DNA features in over $99 \%$ of cervical cancer cases; however, the most common high-risk serotype varies across countries, ethnicities and socioeconomic statuses. In a study of more than 30,000 cervical cancers, the International Agency for Research on Cancer (IARC) demonstrated that amongst the most common HPV serotypes responsible for causing cervical malignancy $(16,18,58,33,45,31,52,35$, $59,39,51,56)$, HPV 16 causes over 50\% whilst HPV 16 and 18 cause more than $70 \%$ of cases worldwide. HPV serotypes 18 and 45 are implicated in the more aggressive cervical adenocarcinomas.

It has been found that sustained infection with high-risk HPV serotypes is the most fundamental risk factor in the development of precursor lesions for cervical cancer. Persistence is normally defined as the detection of the same high-risk HPV types at $>2$ visits $4-6$ months apart. ${ }^{6}$ In fact, studies have shown that such persistent infections can increase the likelihood of developing high-grade precursors of cervical malignancy by more than 10 times. $^{6}$

\section{Pathophysiology}

\section{The Cervical Canal and Associated Malignancies}

The cervix represents the anatomical transition between the vagina and the uterus. It consists of a canal with two openings: the superior internal os which leads into the uterus and the inferior external os that opens into the vaginal cavity. The histology of the cervical canal is characterized by simple columnar secretory epithelium, as opposed to the vaginal cavity, which is lined by stratified non-keratinizing squamous epithelium. The epithelia lining the endocervix and exocervix meet at a point known as the transition zone, or squamocolumnar junction which corresponds to the region of the cervix at the external os. ${ }^{8}$

Figure 2. Life-cycle of the Human Papillomavirus

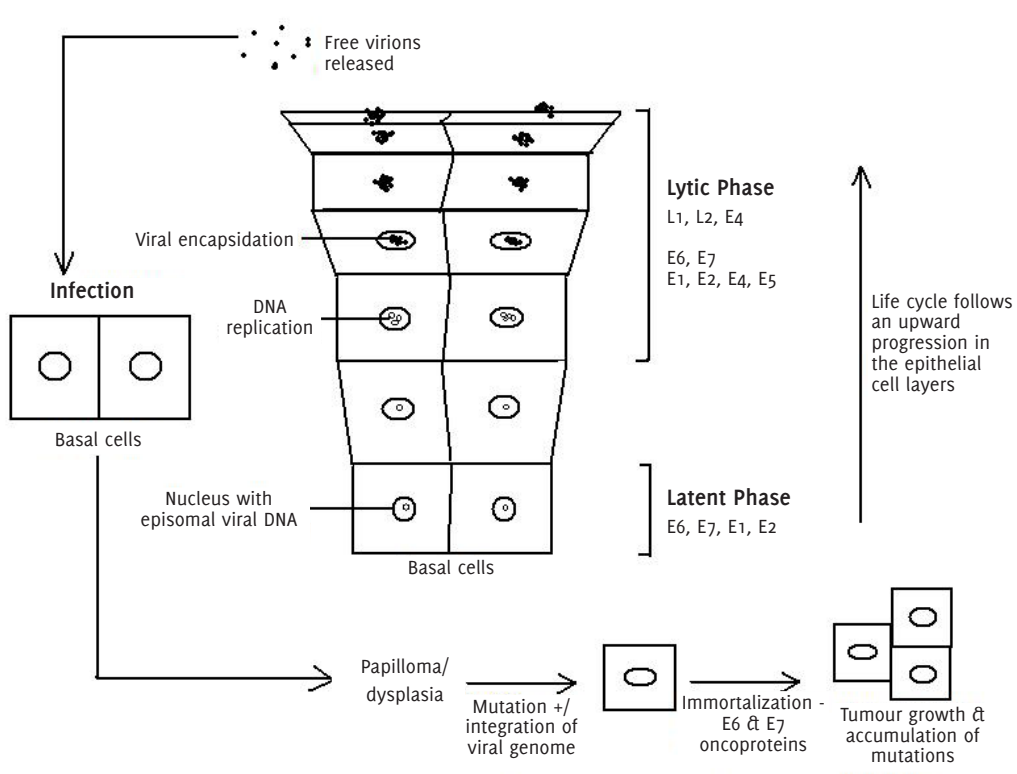

Compiled using information from Narisawa-Saito M, Kiyono T. Basic mechanisms of high-risk human papillomavirus-induced carcinogenesis: roles of E6 and E7 proteins. Cancer Sci. 2007 0ct;98(10):1505-11.
The squamocolumnar junction is a highly important cytological landmark because it is the site with greatest susceptibility to infection by HPV and where over $90 \%$ of malignancies from the lower genital tract arise. HPV is known to cause cervical dysplasia and cervical intraepithelial neoplasia (CIN), which are likely to progress to cervical cancer as a result of sustained infection by high-risk HPV. ${ }^{9}$

As the transition zone involves two epithelial cell types-the glandular and squamous cells-two types of cancers can arise in the cervix. The uncontrolled proliferation of the glandular cells of the endocervix produces an adenocarcinoma (10-20\% of cases, but incidence seems to be on the rise in recent years), whereas a malignancy of the squamous cells results in squamous cell carcinoma. The latter is far more common ( $80-90 \%$ of cases) and is often asymptomatic at its initial stages, but can present with coital and pelvic pain as well as aberrant vaginal bleeding and discharge at later stages.

\section{Life Cycle of the HPV}

The process of cervical carcinogenesis is intimately linked to the events occurring in the life cycle of the virus, as shown in Figure 2. In a stratified squamous epithelium, the cells forming the basal layer behave as stem cells and therefore have the function to undergo cell division in view of replenishing the cells shed from the surface layer. When the basal cell divides by mitosis, two daughter cells are produced: one ascends and transforms into a terminally differentiated cell, whilst the remaining cell resides in the basal layer to maintain the pool of dividing cells. The first targets of the virus are in fact the basal cells that are accessed through microwounds. HPV virions enter the cells by interacting with specific receptors like the alpha- 6 integrin that binds HPV- 16 . Viral DNA replication commences in the basal layers, producing 50-100 copies of the genome in each cell. This is accompanied by the expression of the $E_{1}$ and E2 proteins, which are necessary for the replication process and for the segregation of newly synthesized DNA, thus ensuring that infected stem cells remain in the lesion for a prolonged timeframe. The virus mainly utilizes host machinery to carry out DNA replication, except for the E1 helicase. The products of early genes such as $E_{5}-E_{7} 7$ are thought to create an optimal environment for replication to occur, for example, by stimulating DNA replication in the host cell and preventing apoptosis. $^{9}$

As the infected basal cells migrate upwards and differentiate, the viral late genes $L_{1}$ and $L_{2}$ are transcribed, thereby inducing the vegetative stage of the life cycle characterized by drastic amplification of the genome. ${ }^{9}$ It appears that the control of the expression of the late genes depends on the state of differentiation of the host cell. ${ }^{4}$ Once the cell reaches the outermost layer of the epithelium, the newly synthesized viral DNA is encapsidated to form new virions, which are released, and the life cycle is then repeated. As HPVs do not induce complete lysis in host cells, new virions are deposited in squames that are continuously shed. ${ }^{10}$ It is interesting to note that the virus is well secluded from the host immune system, as the immunogenic virions are only assembled in the outer layers of the epithelium. Furthermore, the viral proteins E6 and E7 also function in keeping the infection asymptomatic by inactivating interferon regulatory factor. ${ }^{9}$ 
Squamous epithelial cells that have been infected by HPV undergo koilocytosis to form cells called koilocytes. These cells have an enlarged, darkened and irregularly outlined nucleus surrounded by an area of clear space called a perinuclear halo and appear vacuolated. This transformation indicates mild cellular dysplasia and represents a highly replicative viral state. When the extent of dysplasia is moderate or severe, cells appear small and multiply even on the outermost layer of the epithelium, making the lesion possibly carcinogenic if severe."

\section{The Role of HPV in Cervical Carcinogenesis}

Although HPV is the major risk factor for cervical cancer, many researchers speculate that the actual integration of viral DNA in the host cell is not a common event and, most of the time, HPV infection is resolved relatively quickly by the immune system. Even though the viral DNA can cause rapid neoplastic transformation of the infected cells once integrated, the presence of HPV DNA in the cell alone is not sufficient to cause cancer because other genetic and epigenetic events are probably required. 9

The two major oncogenic protein products of the HPV virus are $\mathrm{E} 6$ and $\mathrm{E}$, which function by altering the regulation of the cell cycle and the control of apoptosis. The integration of viral DNA disturbs the activity of the E2 protein. This protein is known to repress the transcription of $E 6$ and $E 7$ and, therefore, its disruption leads to dysregulated expression of the oncoproteins. Together, these proteins are capable of causing immortalization of cells, which maintain their mitotic ability to produce clones which also possess the immortalized phenotype and fail to undergo terminal differentiation. ${ }^{4}$

\section{The E7 Oncoprotein}

The major characteristic of $\mathrm{E} 7$ that enables it to enhance neoplastic change is its interaction and subsequent inactivation of $\mathrm{pRb}$. The state of phosphorylation of $\mathrm{pRb}$ changes according to the phase of the cell cycle, being dephosphorylated in Coand 61-phases, phosphorylated throughout the S-phase and remains thus until late in the $\mathrm{M}$-phase when it assumes the hypophosphorylated form once again via a specific phosphatase. ${ }^{4}$

When dephosphorylated, $\mathrm{pRb}$ and associated proteins inhibit transcription factors like E2F by binding to them, thereby repressing the expression of genes whose products stimulate DNA synthesis and enhancing the progression of the cell cycle. Conversely, when pRb is phosphorylated by $\mathrm{G}_{1}$ CDKs, it is unable to bind to E2F and its inhibitory effect is thus lifted, allowing the cell to proceed to the S-phase. It is therefore a regulator of the $\mathrm{G}_{1} / \mathrm{S}$ checkpoint. Detection of damaged DNA results in the activation of p53, which in turn activates p21, a CDK-inhibitor. This binds to and inhibits cyclinE-CDK2 and, hence, pRb cannot be phosphorylated, In other words, it can inactivate $\mathrm{E}_{2} \mathrm{~F}$ and block the $\mathrm{G}_{1} / \mathrm{S}$ transition. ${ }^{12}$

The E7 protein can bind to the hypophosphorylated form of $\mathrm{pRb}$. This interferes with the complex formed between $\mathrm{pRb}$ and $\mathrm{E}_{2} \mathrm{~F}$, resulting in the premature progression of the cell into S-phase, thereby favoring DNA synthesis and, consequently, cell division. E7 is also involved in the enhancement of $\mathrm{pRb}$ cleavage from its C-terminal by calpain, which is a cysteine protease activated by calcium. This is in fact a step that must precede the E7-induced proteasomal cleavage of $\mathrm{pRb}$, which involves the $26 \mathrm{~S}$ proteasome. ${ }^{9}$ Interestingly, the actual production of $\mathrm{E} 7$ and its effects on targets like pRb are necessary for the replication and completion of the full life cycle of HPV. ${ }^{10}$

\section{The E6 Oncoprotein}

The E6 protein primarily exerts its neoplastic effect on HPV-infected cells by promoting the ubiquitin-dependent proteosomal degradation of $\mathrm{p} 53,{ }^{9}$ which is a tumor suppressor gene product that protects the cell against the accumulation of harmful mutations that can lead to cancer development. Such mutations can be due to DNA damage by physical and chemical mutagens, as well as errors during DNA replication. When abnormal DNA is detected and p53 is activated, the cell cycle is paused, allowing DNA repair to occur before the cell divides. In certain circumstances, such as when DNA cannot be effectively repaired, apoptosis can be induced for programmed cell death. ${ }^{10}$

The concentration of $\mathrm{p} 53$ in cells containing E6 such as cervical cancer cells is around 2-3 times smaller compared to uninfected cells. Its half-life is also markedly reduced. As a consequence, the normal response to DNA damage mediated by p53 is not carried out. DNA mutations reside in the genome uncorrected and are passed on from one cellular generation to another, resulting in their accumulation over time and hence causing genomic instability. ${ }^{4}$ Apart from the lack of checkpoint surveillance for DNA damage in cancer cells, they also have an intrinsic tendency to favor mutagenesis. ${ }^{10}$

The binding of $E 6$ to $p_{53}$ is not direct and is mediated by E6-associated protein (E6AP), which is an E3 ubiquitin protein ligase. This is part of a class of proteins homologous to the E6-AP carboxyl terminus (HECT) E3 ligases that function in the recognition of substrates by ubiquinylation machinery targeted for proteosomal degradation. Interestingly, the presence of E6 increases the turnover of E6AP, probably as a result of its enhanced enzymatic activity in the HPV-infected cellular environment. ${ }^{4}$

\section{Areas of Current Research}

Current research is focusing on the role played by oxidative stress in HPV-mediated carcinogenesis. Reactive oxygen species induce DNA damage and modulate the viral life cycle. Studies have proposed a link between the oxidative status of infected cells and the persistence or progression of the lesion. oxidative stress also has pro-survival and anti-apoptotic effects on infected cells and contributes to the expression of the E6 and $\mathrm{E} 7$ genes. This appears to be a promising area of study, especially to determine the effects of oxidative stress on chemotherapy response and resistance and its potential as a marker for diagnostic purposes. ${ }^{13}$

Micro-RNAs (miRNAs) appear to have a role in cervical carcinogenesis. They are short strands of non-coding RNA that normally have short half-life and alter gene expression post-transcriptionally. Their deregulation is associated with the onset, progression and metastasis of human tumors, including cervical cancer which exhibits increased and decreased levels of oncogenic or tumor suppressive miRNAs, respectively. The E6 and E7 proteins are able to modulate miRNAs. It is therefore useful 
to determine how they can be used as prognostic biomarkers by comparing miRNA profiles of normal and transformed cells. In addition, future studies can possibly unlock another form of cervical cancer treatment involving RNA modification therapy. ${ }^{14}$

\section{Diagnosis \\ Cytology and Histology}

The introduction of screening programs over the past decades has succeeded in reducing the incidences and mortalities of cervical cancer. ${ }^{15}$ The most common and convenient technique used to assess the cervix for dysplastic cellular changes is the Papanicolau smear. In this procedure, the vaginal orifice is held open by a speculum, and a sample of cells is taken from the squamocolumnar junction by inserting and rotating a spatula through the external os. The smear is fixed onto a slide, stained appropriately and observed under the microscope to observe the morphology of the epithelial cells. The use of a colposcope allows the direct observation of the cervix with a magnified epithelium and the possibility of taking a biopsy.' It has been estimated that $40-50 \%$ of cervical cancers are diagnosed in women who take routine cervical cytology screening ${ }^{16}$ and that four out of five women diagnosed with cancer had not taken the test in the previous five years.'

Liquid-based cytology has permitted the optimization of the quality and consistency of samples by creating uniform cell layers and decreasing the number of poor samples. The presence of koilocytes is indicative of productive HPV infection, whilst persistent infection manifests itself as highly severe changes in the nucleus, mitotic figures and aggregates of pyknotic cells. Different classification methods are used for these observations (see Table 2), but the Bethesda classification is often the preferred one and presents two categories: (1) low grade squamous epithelial neoplasia (LSIL), which encompasses samples with cells having irregular, larger and well-defined nuclei and (2) high grade squamous epithelial neoplasia (HSIL) for samples characterized by poorly differentiated and immature, small cells having distinct cytoplasmic borders and organized in sheets and syncytial groups.'

Table 2. Classification of Cervical Intraepithelial Lesions

\begin{tabular}{|c|c|c|c|}
\hline $\begin{array}{l}\text { Papanicolau } \\
\text { Classification }\end{array}$ & $\begin{array}{l}\text { Dysplasia } \\
\text { Classification }\end{array}$ & Bethesda Classification & Histology Classification \\
\hline 1 & $\begin{array}{l}\text { Negative squa- } \\
\text { mous atypia }\end{array}$ & $\begin{array}{l}\text { NILM (Negative for intraepi- } \\
\text { thelial lesion or malignancy) }\end{array}$ & Negative \\
\hline \multirow[t]{2}{*}{ II } & $\begin{array}{l}\text { Squamous } \\
\text { atypia }\end{array}$ & $\begin{array}{l}\text { ASCUS (Atypical squamous } \\
\text { cell of unknown significance), } \\
\text { ASC-H (Atypical squamous } \\
\text { cells - cannot exclude HSIL) }\end{array}$ & Squamous atypia \\
\hline & Mild & $\begin{array}{l}\text { LSIL (Low grade squamous } \\
\text { intra-epithelial lesions) }\end{array}$ & $\begin{array}{l}\text { CIN1 (Abnormal cells in } 1: 3 \text { of } \\
\text { layers; very unlikely to progress) }\end{array}$ \\
\hline III & Moderate & $\begin{array}{l}\text { HSIL (High grade squamous } \\
\text { intra-epithelial lesions) }\end{array}$ & $\begin{array}{l}\text { CIN2 (Abnormal cells including } \\
\text { mitotic figures in 2:3 of layers } \\
\text { with loss of stratification and } \\
\text { differentiation) CIN3 (Abnormal } \\
\text { cells in all layers; can progress } \\
\text { to invasive cancer if untreated) }\end{array}$ \\
\hline IV & $\begin{array}{l}\text { Severe CIS } \\
\text { (Carcinoma in } \\
\text { situ) }\end{array}$ & HSIL & $\begin{array}{l}\mathrm{CIN}_{3} \text { (Abnormal cells in all } \\
\text { layers; can progress to invasive } \\
\text { cancer if untreated) }\end{array}$ \\
\hline V & Carcinoma & Carcinoma & Carcinoma \\
\hline
\end{tabular}

Compiled using information from Cubie HA. Diseases associated with human papillomavirus infection. Virology. 2013 Oct;445(1-2):21-34.
Histological assessment of samples provides more specific information about the HPV infection by revealing features such as basal hypertrophy, excess surface keratinization and general disruption of the epithelium. Cervical intraneoplasia lesions are graded according to the fraction of epithelium that exhibits abnormalities.'

\section{Biomarkers}

There are various biomarkers that can be used to identify the presence and extent of HPV infection and progression of cervical malignancy. They can be divided into three groups. The first group comprises HPV DNA, RNA and proteins, which prove to be highly sensitive and specific for the diagnosis of CIN2 or worse lesions in women of 30 years or older and in detecting adenocarcinoma. The second group involves cellular biomarkers, which are based on the fact that the E6 and E7 proteins alter several pathways that control the cell cycle. For example, as the inactivation of pRb leads to an increase in the CDK inhibitor p16, the overexpression of this molecule can be detected by immunostaining or enzyme-linked immunosorbent assay (ELI$\mathrm{SA}$ ) and hence serves as a marker of cellular transformation. The last group includes epigenetic biomarkers which reflect the methylation of DNA and hence whether DNA is active or silenced. The state of methylation of the L1 gene appears to be associated with the diagnosis of CIN2. ${ }^{17}$ Table 3 summarizes the different types of biomarkers used in the detection of cervical cancer lesions.

\section{Management}

The prognosis of cervical cancer and the appropriate treatment modality depend on the stage of the cancer, which represents the extent of invasion and spread of the tumor. Although cervical cancer is staged clinically according to International Federation of Obstetrics and Gynecology guidelines, it is classified in three sub-groups for treatment purposes. ${ }^{18}$ The earliest stages $\left(I A_{1}-I I A_{1}\right)$ represent tumors of the upper one-third of the vagina measuring $<4 \mathrm{~cm}$, which are treated surgically by conization with sufficient excision margins for $\mathrm{I}_{1}$ and conization and simple/radical hysterectomy with pelvic lymphadenectomy for $I I A_{2}$. Small volume macroscopic disease $\left(I I A_{1}-B_{1}\right)$ is treated with radical hysterectomy, and radical trachelectomy with lymphadenectomy is used to preserve fertility. ${ }^{15}$ Intermediate stages $\left(\mathrm{IB}_{2}\right.$ - IVA) require primary chemoradiation, ${ }^{18}$ while advanced stages (IVB) and patients with persistent incurable disease receive systemic chemotherapy, including cisplatin, carboplatin, paclitaxel, topotecan and gemcitabine. ${ }^{19}$

Current research is focusing on new molecular targets for cervical cancer treatment, such as the use of epidermal growth factor receptor (EGFR) antagonists like panitumumab and multitargeted tyrosine kinase inhibitors including imatinib and subitinib. ${ }^{18,20}$ In addition, epigenetic therapy appears to be a promising and effective form of treatment for cervical cancer. ${ }^{21}$ Investigations on the effects of adding the antiangiogenesis agent bevacizumab to chemotherapy used in advanced or recurrent disease are also being carried out. ${ }^{22}$

\section{Prevention}

The HPV vaccine is an important means of preventing cervical cancer, especially if combined with a healthy sexual lifestyle and appropriate use of contraceptives. There has been increa- 
sing consideration that vaccinating men against HPV is a wise decision as it serves a two-fold purpose. As HPV serotypes 16 and 18 are implicated in $70 \%$ of anal cancers and precancerous lesions of the penis, the vaccine can reduce the incidence of these malignancies especially in homosexual males who are at increased risk of anal dysplasia. This is also relevant for the heterosexual population which practices anal intercourse, and it has been found that $35.9 \%$ of women and $42.3 \%$ of men between 18-44 years have anal intercourse with partners of the opposite sex. ${ }^{23}$ Furthermore, vaccinating men is also an indirect means of preventing HPV-induced cervical cancer in women, as it is a sexually transmitted disease. ${ }^{24}$ Unfortunately, people in low-income countries are less likely to be vaccinated against HPV due to its relatively high cost. In addition, most women in these countries do not have access to routine screening, with uptake of Pap smear estimated to be $5 \%$ within the past five years. ${ }^{25}$ This results in an overall higher mortality rate from cervical cancer in developing countries.

\section{HPV Vaccines}

There are currently two available vaccines against HPV: Gardasil ${ }^{\circledR}$ by Merck Frost and Cervarix ${ }^{\circledR}$ by GlaxoSmithkline. Both vaccines contain virus-like particles (VLPS) that are synthesized using recombinant DNA technology and consist of the L1 protein component of the viral capsids. ${ }^{25}$ Such VLPs cause great response by the immune system and result in antibody titers which are much higher than those induced by the natural infection. ${ }^{16}$

\section{Quadrivalent Vaccine}

Gardasi $^{\oplus}$ is said to be a quadrivalent vaccine because it targets four HPV serotypes, namely $6,11,16$ and 18 . The L1 capsid proteins are synthesized in yeast cells (Saccharomyces cerevisae) and combined with an aluminum adjuvant. It is recommended for both sexes of ages 9-26 years and is administered in three doses at 0,2 and 6 months. This vaccine can grant protection against ongoing HPV infection, precancer lesions of the cervix, vulva and vagina, as well as genital warts due to serotypes 11,16 and 18 in females of ages $16-26$ years without previous infection. ${ }^{26}$

\section{Bivalent Vaccine}

On the other hand, Cervarix ${ }^{\circledR}$ is a bivalent vaccine which grants protection against two serotypes-HPV 16 and 18. The VLPs in this preparation are produced in insect cells using baculovirus with an adjuvant consisting of $\mathrm{ASO}_{4}$ and monophosphoryl lipid A from bacterial cell walls. ${ }^{16,26}$ The vaccine is indicated for girls/ women aged 10-25 years and is administered in three doses at 0,1 and 6 months. Randomized, controlled and double-blind studies with women aged 15-25 years demonstrated that the vaccine is efficient in preventing precursor lesions of cervical cancer due to HPV 16 and 18 in women having no previous infection. ${ }^{26}$

When observing the variation of antibody titer with time after the Gardasi $^{\otimes}$ vaccine is administered, it is interesting to note that the variation in titer values after the Cervarix ${ }^{\circledR}$ vaccine follows the same profile, except for two differences. First, 24 months after vaccination with Gardasil ${ }^{\oplus}, 96 \%$ of participants tested positive for HPV types 6, 11 and 16 antibodies and 68\% for type 18. Seropositivity reaches $100 \%$ for both HPV- 16 and HPV- 18 antibodies at 51-53 months after vaccination. Second, the plateau
Table 3. Cervical Cancer Biomarkers

\begin{tabular}{|c|c|c|}
\hline $\begin{array}{l}\text { Type of } \\
\text { Biomarker }\end{array}$ & Test/Technique & Remarks \\
\hline \multirow{4}{*}{$\begin{array}{l}\text { HPV DNA } \\
\text { testing }\end{array}$} & Hybrid Capture 2 (Qiagen) & Detects 13 high-risk HPVs \\
\hline & Cervista HPV HR (Hologic) & Detects 14 high-risk HPVs \\
\hline & $\begin{array}{l}\text { Cervista HPV 16/18 } \\
\text { (Hologic) }\end{array}$ & Specifically identifies HPV 16 and 18 \\
\hline & $\begin{array}{l}\text { Cobas } 4800 \text { HPV (Roche } \\
\text { Diagnostics) }\end{array}$ & Targets 14 high-risk HPVs \\
\hline \multirow[t]{2}{*}{$\begin{array}{l}\text { HPV RNA } \\
\text { testing }\end{array}$} & $\begin{array}{l}\text { APITMA (GenProbe) and } \\
\text { OncoTect (IncellDX) }\end{array}$ & $\begin{array}{l}\text { Based on reverse transcriptase and PCR technique and } \\
\text { detect E6/E7 mRNA from } 14 \text { and } 13 \text { high-risk HPA sero- } \\
\text { types, respectively }\end{array}$ \\
\hline & $\begin{array}{l}\text { PreTect HPV-Proofer (Nor- } \\
\text { chip) and NucliSENS EasyQ } \\
\text { (Biomerieux) }\end{array}$ & $\begin{array}{l}\text { Rely on nucleic acid sequence-based amplification (NAS- } \\
\text { BA) and are able to detect E6/E7 transcripts from HPV } 16 \text {, } \\
18,31,33,45\end{array}$ \\
\hline \multirow[t]{2}{*}{$\begin{array}{l}\text { HPV protein } \\
\text { testing }\end{array}$} & $\begin{array}{l}\text { OncoE6 (Arbor Vita Cor- } \\
\text { poration) }\end{array}$ & Detects E6 protein encoded by HPV $16,18,45$ \\
\hline & $\begin{array}{l}\text { Cytoactiv Assay (Cytoim- } \\
\text { mune Diagnostics) }\end{array}$ & $\begin{array}{l}\text { Measures loss of expression of } L 1 \text { which has been identi- } \\
\text { fied as a potential marker progressive lesions }\end{array}$ \\
\hline \multirow[t]{3}{*}{$\begin{array}{l}\text { Cellular } \\
\text { biomarkers }\end{array}$} & $\begin{array}{l}\text { P16/K1-67 Immunocyto- } \\
\text { chemistry Assay }\end{array}$ & $\begin{array}{l}\text { P16 is a CDK-I whilst } K_{1}-67 \text { is a proliferation antigen } \\
\text { expressed in the } G_{2} \text { and } M \text { phases of the cell cycle. They } \\
\text { are co-expressed in dysplastic lesions and constitute } \\
\text { a highly sensitive and specific test for CIN2 or worse } \\
\text { lesions }\end{array}$ \\
\hline & $\begin{array}{l}\text { ProExCTM Assay (Bec- } \\
\text { ton-Dickinson) }\end{array}$ & $\begin{array}{l}\text { Recognizes minichromosome maintenance protein } 2 \\
\text { and topoisomerase II } \alpha \text {, which are expressed in cells } \\
\text { with abnormal S-phases such as HPV-infected cells with } \\
\text { increased E6/E7 synthesis. }\end{array}$ \\
\hline & $\begin{array}{l}\text { Fluorescence In Situ } \\
\text { Hybridization (FISH) and } \\
\text { Multiplex Ligation-Depen- } \\
\text { dent Probe Amplification } \\
\text { (MLPA) }\end{array}$ & $\begin{array}{l}\text { Can be used to detect gain of chromosomes } 39 \text { and } 5 p \\
\text { which carry the TERC and TERT genes }\end{array}$ \\
\hline \multirow[t]{3}{*}{$\begin{array}{l}\text { Epigenetic } \\
\text { biomarkers }\end{array}$} & $\begin{array}{l}\text { Differential Methylation } \\
\text { Hybridization }(\mathrm{DMH})\end{array}$ & $\begin{array}{l}\text { Allows identification of } S_{0} X_{1}, N K X_{6}-1, P A X_{1}, W X_{1} \text { and } \\
\text { LMXIA genes that are often methylated in cervical cancer } \\
\text { and precancerous lesions }\end{array}$ \\
\hline & $\begin{array}{l}\text { Restriction Landmark Ge- } \\
\text { nomic Scanning (RLCS) }\end{array}$ & Detection of methylated NOL4 and LHFPL4 genes \\
\hline & $\begin{array}{l}\text { Demethylating agent }+ \\
\text { expression microarray }\end{array}$ & Identifies methylation of SPARC and TFP2 genes \\
\hline
\end{tabular}

Compiled using information from Tornesello ML, Buonaguro L, Giorgi-Rossi P, Buonaguro FM. Viral and cellular biomarkers in the diagnosis of cervical intraepithelial neoplasia and cancer. Biomed Res Int. 2013;2013:519619.

level reached with Gardasil ${ }^{\circledR}$ is similar to the titers that are naturally induced by types 6 and 18 and greater for types 11 and 16 , whereas the plateau level with Cervarix ${ }^{\circledR}$ is much higher than that caused by the natural infection. ${ }^{16}$

\section{Contraindications and Side Effects}

The vaccine is contraindicated in people with allergies to any of its components, and women should not be vaccinated during pregnancy even though it does not appear to increase the incidence of miscarriage. ${ }^{26,27}$ Furthermore, people with immediate hypersensitivity towards yeast should not receive the Gardasil vaccine. The vaccine is not contraindicated for immunosuppressed individuals or those with previous HPV infection, although immunogenicity is not guaranteed for the former class. Other vaccines may be administered before, during and after the course of HPV vaccination. ${ }^{26}$ Side effects which have been reported for the quadrivalent vaccine are: (1) pain, swelling and redness at the injection site and headache in more than $10 \%$ of receivers; (2) bruising, itching, fever and nausea in more than $0.1 \%$; (3) urticaria in less than $0.1 \%$; and (4) bronchospasm in less than $0.01 \% .^{28}$ 


\section{Conclusion}

HPV infection plays an integral role in the development of cervical neoplasia. However, modern screening procedures coupled with the promotion of safe sexual practices and HPV vaccination can reduce the burden of this disease.

\section{References}

1. Cubie HA. Diseases associated with human papillomavirus infection. Virology. 2013 Oct; 445 (1-2):21-34.

2. Cubie HA, Cuschieri KS, Tong CYW. Papillomaviruses and polyomaviruses. In: Greenwood D, Barer M, Slack R, Irving W, eds. Medical microbiology. 18th ed. United Kingdom: Churchill Livingstone Elsevier; 2012.

3. IARC Working Group on the Evaluation of Carcinogenic Risks to Humans. Human papillomaviruses. United Kingdom: World Health Organization, International Agency for Research on Cancer; 1995.

4. Howley PM. Warts, cancer and ubiquitylation: lessons from the papillomaviruses. Trans Am Clin Climatol Assoc. 2006;117:113-26; discussion 126-7. 5. Blundell R, Camilleri G. The human papillomaviruses (HPVs) and HPV DNA testing. In: Blundell R, ed. Infertility. Saarbrücken (Germany): Lambert Academic Publishing; 2013. p. 57-82.

6. Dunne EF, Markowitz LE. Genital human papillomavirus infection. Clin Infect Dis. 2006 Sep 1;43(5):624-9.

7. Cason J, Rice P, Best JM. Transmission of cervical cancer-associated human papilloma viruses from mother to child. Intervirology. 1998;41(4-5):213-8.

8. Ferenczy A, Wright TC. Anatomy and histology of the cervix. In: Blaustein A, Kurman RJ, ed. Blaustein's pathology of the female genital tract. USA: Springer; 2002. p. 207-24.

9. Narisawa-Saito M, Kiyono T. Basic mechanisms of high-risk human papiIlomavirus-induced carcinogenesis: roles of E6 and E7 proteins. Cancer Sci. 2007 0ct;98(10):1505-11.

10. Munger K, Basile JR, Duensing S, Eichten A, Gonzalez SL, Grace M, et al. Biological activities and molecular targets of the human papillomavirus E7 oncoprotein. Oncogene. 2001 Nov 26;20(54):7888-98.

11. Blundell R, Camilleri $G$. The mechanisms of HPV-induced carcinogenesis and the HPV vaccine. In: Blundell R, ed. Infertility. Saarbrücken (Germany): Lambert Academic Publishing; 2013. p. 83-100.

12. Shackelford RE, Kaufmann WK, Paules RS. Cell cycle control, checkpoint mechanisms, and genotoxic stress. Environ Health Perspect. 1999 Feb;107 Suppl 1:5-24.

13. De Marco F. Oxidative stress and HPV carcinogenesis. Viruses. 2013 Feb 12;5(2):708-31
14. Gomez-Comez Y, Organista-Nava J, Gariglio P. Deregulation of the miRNAs expression in cervical cancer: human papillomavirus implications. Biomed Res Int. 2013;2013:407052

15. Martin-Hirsch PL, Wood NJ. Cervical cancer. BMJ Clin Evid. 2011 Jul 27;2011: 0818.

16. Dawar M, Deeks S, Dobson S. Human papillomavirus vaccines launch a new era in cervical cancer prevention. CMAJ. 2007 Aug 28;177(5):456-61.

17. Tornesello ML, Buonaguro L, Giorgi-Rossi P, Buonaguro FM. Viral and ceIlular biomarkers in the diagnosis of cervical intraepithelial neoplasia and cancer. Biomed Res Int. 2013;2013:519619.

18. Duenas-Gonzalez A, Serrano-Olvera A, Cetina L, Coronel J. New molecular targets against cervical cancer. Int J Womens Health. 2014 Dec 5;6:1023-31. 19. Scatchard K, Forrest JL, Flubacher M, Cornes P, Williams C. Chemotherapy for metastatic and recurrent cervical cancer. Cochrane Database Syst Rev. 2012 Oct 17;10:CDo06469.

20. Candelaria M, Arias-Bonfill D, Chavez-Blanco A, Chanona J, Cantu D, Perez $C$, et al. Lack in efficacy for imatinib mesylate as second-line treatment of recurrent or metastatic cervical cancer expressing platelet-derived growth factor receptor alpha. Int J Gynecol Cancer. 2009 Dec;19(9):1632-7.

21. Duenas-Gonzalez A, Lizano M, Candelaria M, Cetina L, Arce C, Cervera E. Epigenetics of cervical cancer. An overview and therapeutic perspectives. Mol Cancer. 2005 Oct 25;4:38.

22. Tewari KS, Sill MW, Long HJ 3rd, Penson RT, Huang H, Ramondetta LM, et al. Improved survival with bevacizumab in advanced cervical cancer. $\mathrm{N}$ Engl J Med. 2014 Feb 20;370(8):734-43.

23. Fau CC, Chandra AF, Febo-Vazquez I. Sexual behavior, sexual attraction, and sexual orientation among adults aged 18-44 in the United States: data from the 2011-2013 National Survey of Family Growth. National Health Statistics Reports JID - 1014795190115.

24. Geipert N. Vaccinating men for HPV: new strategy for preventing cervical cancer in women? J Natl Cancer Inst. 2005 May 4;97(9):630-1.

25. Katz IT, Wright AA. Preventing cervical cancer in the developing world. N Engl J Med. 2006 Mar 16;354(11):1110.

26. Mello CF. Vaccination against human papillomavirus. Einstein (Sao Paulo). 2013 Dec;11(4):547-9.

27. Schiller JT, Castellsague X, Garland SM. A review of clinical trials of human papillomavirus prophylactic vaccines. Vaccine. 2012 Nov 20;30 Suppl 5:F123-38.

28. Kitchener H, Almonte M, Wheeler P, Desai M, Gilham C, Bailey A et al. HPV testing in routine cervical screening: cross sectional data from the ARTISTIC trial. Br J Cancer. 2006;95(1):56-61.

\section{Acknowledgments}

None.

Conflict of Interest Statement at Funding

The author has no funding, financial relationships or conflicts of interest to disclose.

Author Contributions

Conceptualization, Data collection, Data analysis and interpretation, Writing, Critical revision of the manuscript, Approval of the final version: $\mathrm{KB}, \mathrm{RB}$.

Cite as:

Bonello K, Blundell R. The role of the human papillomavirus (HPV) in cervical cancer: a review about HPV-induced carcinogenesis and its epidemiology, diagnosis, management and prevention. Int J Med Students. 2016 Jan-Apr;4(1):26-32. 